\title{
Can SHED or DPSCs be used to repair/ regenerate non-dental tissues? A systematic review of in vivo studies
}

Felipe Perozzo DALTOÉ(a) Priscila Pedra MENDONÇA(b) Andrea MANTESSO(c) Maria Cristina Zindel DEBONI(d)

(a) Department of Pathology, Universidade Federal de Santa Catarina, UFSC, Florianópolis, SC, Brazil.

(b)Department of Surgery, School of Veterinary Medicine and Animal Science, Universidade de São Paulo - USP, São Paulo, SP, Brazil.

(c)Department of Oral Pathology, School of Dentistry, Universidade de São Paulo - USP, São Paulo, SP, Brazil.

(d)Department of Oral Surgery, Dental School, Universidade de São Paulo - USP, São Paulo, SP, Brazil.

Declaration of Interests: The authors certify that they have no commercial or associative interest that represents a conflict of interest in connection with the manuscript.

Corresponding Author:

Maria Cristina Zindel Deboni

E-mail: mczdebon@usp.br

DOI: 10.1590/1807-3107BOR-2014.vol28.0037 Epub XXXXX, 2014

Submitted: May 11, 2013

Accepted for publication: May 06, 2014

Last revision: Jul 24, 2014

\begin{abstract}
Dental pulp has been identified as a novel and promising stem cell source. The following systematic review presents and summarises in vivo studies that have used stem cells from the dental pulp of permanent and deciduous teeth to repair or regenerate non-dental tissues. An electronic customised search was performed using 4 different databases (Entrez PubMed, Cab Abstracts, Scopus and Web of Science). Only full-text research manuscripts published in English between the years of 2000 and 2012 were included. The manuscripts were retrieved based on the following keywords and/or abbreviations: [Stem Cells from Human Exfoliated Deciduous teeth (SHED)] AND/OR [Dental Pulp Stem Cells (DPSC)] AND [tissue regeneration] AND [tissue repair]. Only manuscripts involving in vivo applications of SHED or DPSC for the repair and/or regeneration of non-dental tissues were included. The search strategy produced 2309 papers, from which 14 were eligible according to the predetermined inclusion and exclusion criteria. Although human tissue was the source of cells in half of the studies included in our review, all of the studies involved transplantation into animals of other species, such as pigs, rats and mice. Most of the manuscripts reported the successful use of DPSCs or SHED for non-dental tissue repair or regeneration. While these cell populations represent promising alternative sources of stem cells for tissue engineering and cell-based regenerative medicine therapies, it is not yet possible to guarantee the appropriate clinical management of this technique.
\end{abstract}

Keywords: Stem Cells; Dental Pulp; Tooth, Deciduous.

\section{Introduction}

Stem cells are a promising tool for the treatment of many different human diseases. An enormous variety of stem cells have been isolated and studied from different tissues, such as bone marrow, ${ }^{1}$ adipose tissue, ${ }^{2}$ skin, ${ }^{3}$ and umbilical cord. ${ }^{4}$ Among them, mesenchymal stem cells (MSCs) are the most promising for clinical purposes. ${ }^{5}$

Recently, MSCs were identified in the dental pulp. These cells represent a novel and promising stem cell population with self-renewal and multilineage differentiation capacities that are similar to other MSC populations. ${ }^{6,7}$ Since the discovery of stem cells in the dental pulp of permanent ${ }^{6}$ and deciduous teeth, ${ }^{8}$ a large number of animal studies have evaluated the suitability of these cells for dental ${ }^{9}$ as well as non-dental ${ }^{10,11}$ tissue engineering applications. Here, we present a systematic review of in vivo studies investigat- 
ing the use of dental pulp stem cells for the repair or regeneration of non-dental tissues.

\section{Methodology}

Two independent researchers, following the PRISMA guidelines, ${ }^{12}$ carried out an electronic customised search of scientific papers published between 2000 and 2012 using the Entrez PubMed, CAB Abstracts, Scopus and Web of Science databases. The following combination of keywords and abbreviations was used: [Stem Cells from Human Exfoliated Deciduous teeth (SHED)], [Dental Pulp Stem Cells (DPSC)] AND [tissue regeneration] AND [tissue repair]. Only full-text research manuscripts that were written in English and described in vivo analysis of tissue repair and/or regeneration of non-dental tissues using SHED or DPSCs were included in this review. Duplicate papers were excluded.

\section{Results}

Our search yielded a total of 2309 papers. Based on the abstracts, 1072 papers were excluded according to the previously mentioned inclusion/exclusion cri- teria. An additional 1221 papers were determined to be duplicates and were also excluded. Finally, of the 16 selected manuscripts, 2 were excluded because the full-text was not available in English. Thus, 14 manuscripts formed the basis of this review (Figure 1). The included manuscripts are summarised in Table 1.

In 7 of the studies included in this review (50\%), the cells were isolated from human tissue. In all 14 studies, the cells were transplanted into animals of other species, including pigs, rats and mice.

Eight manuscripts investigated bone tissue repair and/or regeneration. Liu et al., ${ }^{10}$ Seo et al.,$^{13}$ de Mendonça Costa et al. ${ }^{14}$ and Riccio et al.,$^{15}$ investigated new bone formation in critical-size calvarial bone defects, while Yamada et al.,16 and Zheng et al., ${ }^{17}$ studied critical-size mandibular bone defect repair. Ito $e t$ al., ${ }^{18}$ studied the osseointegration of dental implants and Zhang et al., ${ }^{19}$ investigated bone formation by subcutaneously implanted DPSCs. In these studies, the association of the stem cells with scaffolds, growth factors or recombinant proteins was common. Hydroxyapatite/tricalcium phosphate (HA/
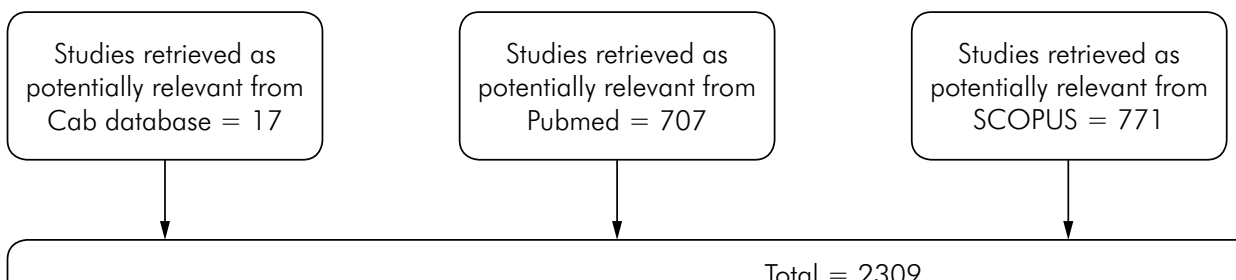

Studies retrieved as potentially relevant from WEB SCI $=814$

Total $=2309$
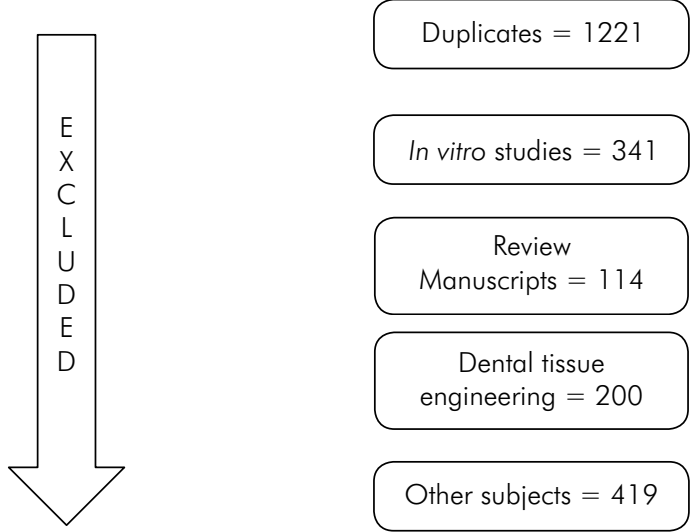

Appropriate studies retrivedand include in this review $=14$

Figure 1. Flow diagram presenting the results of the literature search and the process used to select studies for the systematic review. 
Table 1. Studies that used SHED or DPSCs for the repair and/or regeneration of non-dental tissues.

\begin{tabular}{|c|c|c|c|c|c|}
\hline Author(s) & Targeted site & Intervention & Host & Scaffolds & Outcome \\
\hline Riccio et al. $2012^{15}$ & $\begin{array}{c}\text { Critical-size cranial bone } \\
\text { defect }\end{array}$ & Human DPSCs & Rat & $\begin{array}{l}\text { Fibroin } \\
\text { scaffolds }\end{array}$ & $\begin{array}{l}\text { Mature bone } \\
\text { formation and } \\
\text { defect correction }\end{array}$ \\
\hline Sakai et al. $2012^{21}$ & Transected spinal cord & $\begin{array}{l}\text { Human DPSCs and } \\
\text { SHED }\end{array}$ & Rat & None & $\begin{array}{l}\text { Recovery of hind limb } \\
\text { locomotor function } \\
\text { r functions }\end{array}$ \\
\hline Liv et al. $2011^{10}$ & $\begin{array}{c}\text { Critical-size alveolar bone } \\
\text { defect }\end{array}$ & Rabbit DPSCs & Rabbit & $\begin{array}{l}\mathrm{rhBMP}-2+ \\
\mathrm{nHAC} / \mathrm{PL}\end{array}$ & $\begin{array}{l}\text { Full tissue repair, but } \\
\text { DPSCs were not necessary for } \\
\text { regeneration }\end{array}$ \\
\hline Yamada et al. $2011^{16}$ & Mandibular bone defect & $\begin{array}{l}\text { Canine DPSCs and } \\
\text { canine deciduous } \\
\text { teeth stem cells }\end{array}$ & Dog & PRP & $\begin{array}{l}\text { Well-formed } \\
\text { mature bone using } \\
\text { both cell lines }\end{array}$ \\
\hline Nishino et al. $2011^{24}$ & Skin defect & SHED & Mouse & None & $\begin{array}{l}\text { hDPSCs accelerated skin } \\
\text { wound healing }\end{array}$ \\
\hline Ito et al. $2011^{18}$ & $\begin{array}{l}\text { Osseointegration of dental } \\
\text { implants }\end{array}$ & Canine DPSCs & Dog & PRP & $\begin{array}{l}\text { High osteogenic } \\
\text { potential of DPSCs } \\
\text { contributed to dental } \\
\text { implant integration }\end{array}$ \\
\hline Arthur et al. $2009^{20}$ & $\begin{array}{c}\text { Axon guidance in the central } \\
\text { nervous system }\end{array}$ & Human DPSCs & Chick & None & $\begin{array}{l}\text { DPSCs may induce } \\
\text { neuroplasticity within the } \\
\text { receptive host } \\
\text { nervous system }\end{array}$ \\
\hline Zheng et al. $2009^{17}$ & Orofacial bone defects & $\begin{array}{l}\text { Porcine deciduous } \\
\text { teeth stem cells }\end{array}$ & Minipig & $\beta$-ТCP & $\begin{array}{l}\text { More efficient regeneration } \\
\text { of critical-size mandibular } \\
\text { bone defects }\end{array}$ \\
\hline lohara et al. $2008^{23}$ & $\begin{array}{l}\text { Angiogenesis in mouse hind } \\
\text { limb ischemia model }\end{array}$ & $\begin{array}{c}\text { Porcine DPSCs and } \\
\text { porcine deciduous } \\
\text { teeth } \\
\text { stem } \\
\text { cells }\end{array}$ & Mouse & None & $\begin{array}{l}\text { Increase in blood flow due to } \\
\text { new capillary formation }\end{array}$ \\
\hline Seo et al. $2008^{13}$ & $\begin{array}{c}\text { Critical-size calvarial bone } \\
\text { defect }\end{array}$ & SHED & Mouse & $\mathrm{HA} / \mathrm{TCP}$ & $\begin{array}{l}\text { Repair of the defects and } \\
\text { substantial bone formation }\end{array}$ \\
\hline Zhang et al. $2008^{19}$ & $\begin{array}{l}\text { Mineralisation in } \\
\text { subcutaneous } \\
\text { implants }\end{array}$ & $\begin{array}{c}\text { Rat DPSCs and human } \\
\text { DPSCs }\end{array}$ & $\begin{array}{l}\text { Nude } \\
\text { mouse }\end{array}$ & $\mathrm{HA} / \mathrm{TCP}$ & No bone formation \\
\hline Sasaki et al. $2008^{11}$ & $\begin{array}{l}\text { Peripheral nerve } \\
\text { regeneration }\end{array}$ & Rat DPSCs & Rat & Silicone tube & $\begin{array}{l}\text { Formation of blood } \\
\text { vessels } \\
\text { and myelinating } \\
\text { tissue, but no axonal } \\
\text { regeneration }\end{array}$ \\
\hline $\begin{array}{l}\text { de Mendonça Costa et al. } \\
2008^{14}\end{array}$ & Cranial bone defect & SHED & Rat & $\begin{array}{l}\text { Collagen } \\
\text { membrane }\end{array}$ & $\begin{array}{l}\text { Increased formation of mature } \\
\text { bone }\end{array}$ \\
\hline Gandia et al. $2008^{22}$ & Acute myocardial Infarction & Human DPSCs & $\begin{array}{c}\text { Nude } \\
\text { Rat }\end{array}$ & None & $\begin{array}{l}\text { Improvement of left } \\
\text { ventricular function, } \\
\text { angiogenesis, and } \\
\text { reduction of infarct size }\end{array}$ \\
\hline
\end{tabular}

* The term SHED refers only to human derived cells.

$\mathrm{TCP}),{ }^{13,18}$ recombinant human nanohydroxyapatite/ collagen/poly (L-lactide) (nHAC/PLA), ${ }_{10}^{10}$ platelet-rich plasma (PRP), fibrin, ${ }^{17}$ bone morphogenetic protein 2 (rhBMP-2) $)^{10}$ and collagen membranes ${ }^{16}$ were used. Three groups of researchers used cells from deciduous teeth in their experiments, 3 groups used cells from permanent teeth and the remaining 2 groups compared both types of cells. Notably, both sources of cells (i.e., the pulp of deciduous and permanent teeth) presented bone-formation capacity ${ }^{13,14,15,16,18}$ and, in some cases, their osteogenic ability was superior to that of bone marrow-derived SCs. ${ }^{14,15}$ 
In addition, DPSCs were shown to promote the repair of facial nerve gaps in rats ${ }^{11}$ and induce neuroplasticity within the recipient nervous system in chicks. ${ }^{20}$ In another nerve repair study, both SHED and DPSCs promoted the recovery of hind limb locomotor function in rats. ${ }^{21}$ DPSCs also exhibited therapeutic potential for the repair of a myocardial infarction (MI) in a MI mouse model. Although the cells were able to engraft into the infarcted heart, they did not differentiate into cardiac, endothelial or smooth muscle cells. Nevertheless, angiogenesis was increased compared to that observed in animals that received a control treatment. ${ }^{22}$ Angiogenesis was found to be improved when endothelial progenitor cells from swine deciduous and permanent teeth were used to treat ischemia in a hind limb ischemia mouse model, as the cells helped to increase the blood supply and contributed to the formation of a new capillary network. ${ }^{23}$ Lastly, SHED were reported ${ }^{24}$ to help accelerate wound healing when associated with fibroblast growth factor (b-FGF).

\section{Discussion}

Regenerative medicine is defined as the use of a combination of cells, engineering materials and suitable biochemical factors to improve or replace biological function. ${ }^{25}$ Thus, regenerative medicine treatments have the potential to restore damaged tissues and organs. Importantly, the regenerative potential of DPSCs and SHED has been studied in a variety of non-dental tissues. In vivo studies have shown that these cells can form bone, blood vessels, nerves, myocardium and skin. However, the majority of the studies described in the literature have investigated bone formation. $10,13,14,15,16,17,18,19$

Our systematic review aimed to analyse in vivo studies that were performed in humans and animals. The keyword [animals] was not an inclusion criteria, nor was [human] an exclusion one. Nevertheless, we did not find any in vivo studies in humans. Dental stem cells were first isolated from the dental pulp ${ }^{6}$ of permanent teeth and subsequently from the dental pulp of deciduous teeth. ${ }^{8}$ Because of the relative novelty of this research area, there is most likely insufficient research to enable the approval of human testing or clinical protocols.
Apparently, SHED, which can differentiate into neural cells, adipocytes, osteoblasts and odontoblasts ${ }^{8}$ have higher plasticity than DPSCs. In vivo, SHED are capable of spontaneously generating robust amounts of bone ${ }^{8,20}$ while DPSCs can only form bone and dentine. ${ }^{6}$ This difference suggests that DPSCs are distinct from SHED with respect to odontogenic differentiation and osteogenic induction. Furthermore, both DPSCs and SHED have a higher proliferative capacity than other well-known MSCs, such as bone marrow stem cells. ${ }^{6,7}$ SHED, in particular, are considered an outstanding source of stem cells. Considering that humans typically exfoliate 20 deciduous teeth throughout life and quite often have impacted and unerupted third molars extracted for clinical or orthodontic purposes, ${ }^{26,27}$ teeth could represent an important, easily accessible and non-invasive (particularly for the deciduous teeth) source of stem cells.

As previously mentioned, most of the selected manuscripts in this review studied the use of DPSCs and SHED for bone tissue repair or regeneration. . $0,13,14,15,16,17,18,19$ The use of SHED or DPSCs may avoid the inconvenience and morbidity associated with the removal of autogenous grafts from other sites. ${ }^{28}$ Moreover, in contrast to the use of autologous bone grafts, DPSCs or SHED can be expanded in vitro prior to their use in vivo to generate an adequate number of cells for the tissue being repaired. This approach could prevent or decrease problems associated with autogenous grafting techniques, such as the limited amount of tissue that can be removed from the donor site and the risk of infection.

In general, SHED and DPSC-based bone repair/ regeneration strategies were found, at least in animals, to significantly increase bone formation compared to the control groups studied. ${ }^{13,14,15,16,17,19}$ However, Liu et al. ${ }^{10}$ found no significant differences in bone formation when DPSCs associated with nHAC/PLA and rhBMP-2 were used compared to autologous bone. In this study, the nHAC/PLA + DPSCs + rhBMP-2 composite did prove to be suitable for maxillary bone tissue repair, but DPSCs were apparently not required for successful regeneration. Similarly, Zhang et al., ${ }^{19}$ did not observe bone formation when rat or human DPSCs associated with HA/TCP were transplanted subcutaneously in nude mice. However, it should be 
noted that, according to these authors, a high number of cell passages was needed to obtain enough viable cells for the experiments. Furthermore, in contrast to their in vivo experiments, all four types of cells used by Zhang et al., ${ }^{19}$ (i.e., rat bone marrow, rat DPSCs, human bone marrow and human DPSCs) were able to form mineralised tissues in vitro. DPSCs have also attracted interest as an alternative to improve the outcome of dental implants, ${ }^{18}$ and this cell population has been shown to possess higher osteogenic potential than bone marrow stem cells, which are still considered the gold standard for bone tissue formation.

The analysis of the neural repair capacity of DPSCs and SHED was ambiguous, in our opinion, due to the differences in the methodology used by the different authors. ${ }^{11,20,21}$ DPSCs are apparently able to stimulate the formation of blood vessels and myelinating tissue in the peripheral nerves of adult rats. However, the authors did not perform any functional assays to prove a gain of function. ${ }^{11}$ To investigate this limitation, a more recent study showed that engrafted SHED and DPSCs were able to differentiate toward mature oligodendrocytes and promote functional recovery of the peripheral nervous system in hind limb defects in a rat model. The rats that received SHED were able to walk without weight support, while those that received bone marrow stem cells or fibroblasts exhibited only subtle joint movements. ${ }^{21}$

DPSCs have also been reported to have potential for use in cell-based therapies for systemic diseases, such as cardiac disease. ${ }^{22,23}$ When DPSCs were injected into mice with myocardial infarctions, they had a significant effect on recovery compared to the control group. Notably, none of the injected cells differentiated into cardiac, endothelial or smooth muscle cells. Rather, according to the authors, the fact that the treated mice had a significantly improved recovery suggests that DPSCs can contribute to cardiac repair by some other mechanism. ${ }^{22}$ This result agrees with previous reports that support the ability of MSCs to induce cardiac repair, despite extremely rare fusion/ differentiation events. ${ }^{29}$ The benefits resulting from DPSC transplantation were possibly due to the secretion of paracrine factors. ${ }^{22}$

More recently, it has been shown that it is possible to isolate a sub-fraction of endothelial cells from dental pulp tissue based on the expression of cell surface markers. ${ }^{23}$ These cells have been shown to have a high proliferative and migratory capacity as well as multilineage differentiation potential, including angiogenic, chondrogenic, adipogenic, neurogenic and odontogenic-potential. When these cells were applied in a mouse model to reverse hind limb ischemia, the results demonstrated successful engraftment and an increase in blood supply due to the formation of new capillaries. Hence, the use of endothelial progenitor cells derived from dental pulp might represent an alternative approach for the transplantation of autologous endothelial progenitor cells in which cells are obtained by an invasive and potentially painful biopsy procedure. ${ }^{30}$

Lastly, Nishino Y et al., ${ }^{24}$ showed that the use of SHED, in association with basic fibroblasowth factor (b-FGF), in a nude mouse full-thickness skin defect model significantly accelerated wound healing compared with other groups. This work highlights SHED as a promising stem cell population for future wound healing therapies as well.

The lack of a standardised type and pattern of cell types and scaffolds may influence cellular responses and alter their properties for clinical bioengineering. Indeed, the different types of cells and the different structures and porosities of scaffolds and/or delivery systems are some of the issues that complicated comparisons between the studies included in our review. In addition, without standardised protocols that include cell culture conditions, sources, numbers, passages and their adhesion properties on tissue surfaces, it is not possible to guarantee the appropriate clinical management of these techniques.

\section{Conclusion}

In summary, most of the retrieved in vivo studies using SHED or DPSCs focused on bone tissue repair/ regeneration, and the results of these studies indicated that the use of DPSCs and SHED seems to be effective for these applications. However, very few studies were found regarding the potential of these cells to promote functional recovery of neuronal tissue, blood vessels, muscle, cartilage or other tissues. As a result, the potential of DPSCs and SHED for the repair of other non-dental tissues remains unclear. 


\section{References}

1. Ding L, Morrison SJ. Haematopoietic stem cells and early lymphoid progenitors occupy distinct bone marrow niches. Nature. 2013 14;495(7440):231-5.

2. Chen L, Song J, Cui J, Hou J, Zheng X, Li C, et al. MicroRNAs regulate adipocyte differentiation. Cell Biol Int. 2013 Jun;37(6):533-46.

3. Blanpain C, Fuchs E. Epidermal homeostasis: a balancing act of stem cells in the skin. Nat Rev Mol Cell Biol. 2009 Mar;10(3):207-17.

4. Yan M, Sun M, Zhou Y, Wang W, He Z, Tang D, et al. Conversion of human umbilical cord mesenchymal stem cells in Wharton's jelly to dopamine neurons mediated by the Lmx1a and neurturin in vitro: potential therapeutic application for Parkinson's disease in a rhesus monkey model. PLoS One. 2013;8(5):e64000.

5. Ménard C, Tarte K. Immunoregulatory properties of clinical grade mesenchymal stromal cells: evidence, uncertainties, and clinical application. Stem Cell Res Ther. 2013 Jun;4(3):64.

6. Gronthos S, Mankani M, Brahim J, Robey PG, Shi S. Postnatal human dental pulp stem cells (DPSCs) in vitro and in vivo. Proc Natl Acad Sci U S A. 2000 Dec;97(25):13625-30.

7. Seo BM, Miura M, Gronthos S, Bartold PM, Batouli S, Brahim $\mathrm{J}$, et al. Investigation of multipotent postnatal stem cells from human periodontal ligament. Lancet. 2004 Jul;364(9429):149-55.

8. Miura M, Gronthos S, Zhao M, Lu B, Fisher LW, Robey PG, et al. SHED: stem cells from human exfoliated deciduous teeth. Proc Natl Acad Sci U S A. 2003 May;100(10):5807-12.

9. Hu B, Nadiri A, Kuchler-Bopp S, Perrin-Schmitt F, Peters $\mathrm{H}$, Lesot $\mathrm{H}$. Tissue engineering of tooth crown, root, and periodontium. Tissue Eng. 2006 Aug;12(8):2069-75.

10. Liu HC, E LL, Wang DS, Su F, Wu X, Shi ZP, et al. Reconstruction of alveolar bone defects using bone morphogenetic protein 2 mediated rabbit dental pulp stem cells seeded on nano-hydroxyapatite/collagen/ poly(l-lactide). Tissue Eng Part A. 2011 Oct;17(19-20):2417-33.

11. Sasaki R, Aoki S, Yamato M, Uchiyama H, Wada K, Okano T, et al. Tubulation with dental pulp cells promotes facial nerve regeneration in rats. Tissue Eng Part A. 2008 Jul;14(7):1141-7.

12. Moher D, Liberati A, Tetzlaff J, Altman DG; PRISMA Group. Preferred reporting items for systematic reviews and metaanalyses: the PRISMA statement. Ann Intern Med. 2009 Aug;151(4):264-9.

13. Seo BM, Sonoyama W, Yamaza T, Coppe C, Kikuiri T, Akiyama $\mathrm{K}$, et al. SHED repair critical-size calvarial defects in mice. Oral Dis. 2008 Jul;14(5):428-34.

14. de Mendonça Costa A, Bueno DF, Martins MT, Kerkis I, Kerkis A, Fanganiello RD, et al. Reconstruction of large cranial defects in nonimmunosuppressed experimental design with human dental pulp stem cells. J Craniofac Surg. 2008 Jan;19(1):204-10.

15. Riccio M, Maraldi T, Pisciotta A, La Sala GB, Ferrari A, Bruzzesi G, et al. Fibroin scaffold repairs critical-size bone defects in vivo supported by human amniotic fluid and dental pulp stem cells. Tissue Eng Part A. 2012 May;18(9-10):1006-13.
16. Yamada Y, Ito K, Nakamura S, Ueda M, Nagasaka T. Promising cell-based therapy for bone regeneration using stem cells from deciduous teeth, dental pulp and bone marrow. Cell Transplant. 2011 Jan;20(7)1003-13.

17. Zheng Y, Liu Y, Zhang CM, Zhang HY, Li WH, Shi S, et al. Stem cells from deciduous tooth repair mandibular defect in swine. J Dent Res. 2009 Mar;88(3):249-54.

18. Ito K, Yamada Y, Nakamura S, Ueda M. Osteogenic potential of effective bone engineering using dental pulp stem cells, bone marrow stem cells, and periosteal cells for osseointegration of dental implants. Int J Oral Maxillofac Implants. 2011 Sep-Oct; 26(5):947-54.

19. Zhang W, Walboomers F, Van Osch GJVM, Dolder JVD, Jansen AJA. Hard tissue formation in a porous HA/TCP ceramic scaffold loaded with stromal cells derived from dental pulp and bone marrow. Tissue Eng Part A. 2008 Feb;14(2):285-94.

20. Arthur A, Shi S, Zannettino ACW, Fujii N, Gronthos S, Koblar SA. Implanted adult human dental pulp stem cells induce endogenous axon guidance. Stem Cells. 2009 Sep;27(9):2229-37.

21. Sakai K, Yamamoto A, Matsubara K, Nakamura S, Naruse M, Yamagata M, et al. Human dental pulp-derived stem cells promote locomotor recovery after complete transection of the rat spinal cord by multiple neuro-regenerative mechanisms. J Clin Invest. 2012 Jan;122(1):80-90.

22. Gandia C, Armiñan A, García-Verdugo JM, Lledó E, Ruiz A, Miñana D, et al. Human dental pulp stem cells improve left ventricular function, induce angiogenesis, and reduce infarct size in rats with acute myocardial infarction. Stem Cells. 2008 Mar;26(3):638-45.

23. Iohara K, Zheng L, Wake H, Ito M, Nabekura J, Wakita H, et al. A novel stem cell source for vasculogenesis in ischemia: subfraction of side population cells from dental pulp. Stem Cells. 2008 Sep;26(9):2408-18.

24. Nishino Y, Ebisawa K, Yamada Y, Okabe K, Kamei Y, Ueda M. Human deciduous teeth dental pulp cells with basic fibroblast growth factor enhance wound healing of skin defect. J Craniofac Surg. 2011. Mar;22(2):438-42.

25. Murray PE, Garcia-Godoy F, Hargreaves KM. Regenerative endodontics: a review of current status and a call for action. J Endod. 2007 Apr;33(4):377-90.

26. Kaminishi RM,Lam PS,Kaminishi KS,Marshall MW,Hochwald DA A 10-year comparative study of the incidence of third molar removal in the aging population. J Oral Maxillofac Surg. 2006 Feb;64(2):173-4.

27. Dodson TB, Susarla SM. Impacted wisdom teeth. Clin Evid [Internet]. 2010 Apr 8 [cited 201407 22];2010:1302. Available from: http://www.ncbi.nlm.nih.gov/pmc/articles/PMC2907590/.

28. Dinopoulos H, Dimitriou R, Giannoudis PV. Bone graft substitutes: what are the options? Surgeon. 2012 Aug;10(4):230-9. 
29. Miyahara Y, Nagaya N, Kataoka M, Yanagawa B, Tanaka K, Hao $\mathrm{H}$, et al. Monolayered mesenchymal stem cells repair scarred myocardium after myocardial infarction. Nat Med. 2006 Apr;12(4):459-65.
30. Crosby JR, Kaminski WE, Schatteman G, Martin PJ, Raines EW, Seifert RA, et al. Endothelial cells of hematopoietic origin make a significant contribution to adult blood vessel formation. Circ Res. 2000 Oct;87(9):728-30. 